\title{
Article \\ Effect of the Process Atmosphere Composition on Alloy 718 Produced by Laser Powder Bed Fusion
}

\author{
Camille Pauzon ${ }^{1, * \mathbb{D}}$, Andreas Markström ${ }^{2}$, Sophie Dubiez-Le Goff ${ }^{3}$ and Eduard Hryha ${ }^{1}$ \\ 1 Department of Industrial and Materials Science, Chalmers University of Technology, 41296 Göteborg, Sweden; \\ hryha@chalmers.se \\ 2 Thermo-Calc Software AB, 11347 Stockholm, Sweden; andreas@thermocalc.se \\ 3 Linde $\mathrm{GmbH}$, 85716 Unterschleissheim, Germany; sophie.dubiez-le.goff@linde.com \\ * Correspondence: pauzon@chalmers.se
}

check for updates

Citation: Pauzon, C.; Markström, A.; Dubiez-Le Goff, S.; Hryha, E. Effect of the Process Atmosphere Composition on Alloy 718 Produced by Laser Powder Bed Fusion. Metals 2021, 11, 1254. https://doi.org/10.3390/ met11081254

Academic Editor: Aleksander Lisiecki

Received: 7 July 2021

Accepted: 5 August 2021

Published: 7 August 2021

Publisher's Note: MDPI stays neutral with regard to jurisdictional claims in published maps and institutional affiliations.

Copyright: (c) 2021 by the authors. Licensee MDPI, Basel, Switzerland. This article is an open access article distributed under the terms and conditions of the Creative Commons Attribution (CC BY) license (https:// creativecommons.org/licenses/by/ $4.0 /)$.

\begin{abstract}
The detrimental effect of nitrogen and oxygen when it comes to the precipitation of the strengthening $\gamma^{\prime \prime}$ and $\gamma^{\prime}$ phases in Alloy 718 is well-known from traditional manufacturing. Hence, the influence of the two processing atmospheres, namely argon and nitrogen, during the laser powder bed fusion (L-PBF) of Alloy 718 parts was studied. Regardless of the gas type, considerable losses of both oxygen of about $150 \mathrm{ppm} \mathrm{O}_{2}(\approx 30 \%)$ and nitrogen on the level of around $400 \mathrm{ppm}$ $\mathrm{N}_{2}(\approx 25 \%)$ were measured in comparison to the feedstock powder. The utilization of nitrogen as processing atmosphere led to a slightly higher nitrogen content in the as-built material—about $50 \mathrm{ppm}$ - compared to the argon atmosphere. The presence of the stable nitrides and Al-rich oxides observed in the as-built material was related to the transfer of these inclusions from the nitrogen atomized powder feedstock to the components. This was confirmed by dedicated analysis of the powder feedstock and supported by thermodynamic and kinetic calculations. Rapid cooling rates were held responsible for the limited nitrogen pick-up. Oxide dissociation during laser-powder interaction, metal vaporization followed by oxidation and spatter generation, and their removal by processing atmosphere are the factors describing an important oxygen loss during L-PBF. In addition, the reduction of the oxygen level in the process atmosphere from 500 to $50 \mathrm{ppm}$ resulted in the reduction in the oxygen level in as-built component by about $5 \%$.
\end{abstract}

Keywords: additive manufacturing; laser powder bed fusion; process gas; nitrogen; argon; oxygen content; Alloy 718

\section{Introduction}

Additive manufacturing (AM) of Alloy 718, a precipitation-strengthened nickel-iron superalloy, has gained a lot of attention since it offers the possibility to produce complex components with high-temperature mechanical and chemical resistance. The precipitation of the intermetallic $\gamma^{\prime \prime}$ phase $\left(\mathrm{Ni}_{3} \mathrm{Nb}\right)$, in addition to that of the $\gamma^{\prime}$ phase, in the austenitic $\gamma$ matrix confers most of its strength [1]. Until now, Alloy 718 has been preferably produced following the traditional ingot-metallurgy processing route for superalloys, including vacuum induction melting and electroslag refining and/or vacuum arc melting [2], followed by homogenization, forging, and machining to final dimensions. It is known that Alloy 718 is a difficult-to-machine material because of its high strength at elevated temperatures, its low thermal conductivity, high ductility, and critical work hardening [3]. Therefore, the adoption of a near-net shape manufacturing approach such as laser powder bed fusion (L-PBF), allowing to reduce the extent of required machining, is promising. However, many challenges are to be addressed to make L-PBF an economically viable manufacturing route for Alloy 718.

Considerable research efforts are put by the AM community into studying the processmicrostructure-properties relationships of Alloy 718 produced as such [4,5]. Alloy 718 components built by L-PBF in the as-built state typically exhibit a dendritic microstructure 
without the presence of the main strengthening phases $\gamma^{\prime \prime}$ and $\gamma^{\prime}$, and with Laves and MC carbides in the interdendritic regions [6]. The fine dendrite arm spacing (order of hundreds of nanometers [7]) explains its high strength in the as-built state (yield strength of about $1200 \mathrm{MPa}$ [6]). However, the absence of the strengthening phases in as-built conditions makes it unsuitable for intended applications at elevated temperatures, and hence, post-L-PBF heat treatment has to be applied, where extensive focus research is placed as well [6,8-10].

Among the many challenges to tackle, the understanding of the sensitivity of Alloy 718 to the nitrogen and oxygen pick-up during L-PBF processing is of paramount importance for assuring robust fabrication of the high-performance components, with tight requirements for interstitials content. It has already been put in evidence that Alloy 718 powder undergoes significant selective oxidation during electron beam melting (EBM) with the formation of Al-rich oxides [11]. Gruber et al. [12] revealed that the degradation of the used powder and its recycling was associated with the increased presence of oxide inclusions and related lack-of-fusion defects in the as-built material. Recent work by authors with focus on the in-depth characterization of the powder degradation during L-PBF of Alloy 718 highlighted the development of $\mathrm{Al}$ and $\mathrm{Cr}$ oxide patches on the spatters when using $\mathrm{Ar}$ as the processing atmosphere, in addition to the thin $\mathrm{Ni}$ oxide layer characteristic of the feedstock powder [13]. It was shown that spatter particles picked up more than $300 \mathrm{ppm}$ of oxygen from the process atmosphere after one processing cycle. These investigations highlight the sensitivity of Alloy 718 powder to the AM process conditions and particularly to the residual oxygen. It has already been established that the properties of alloys such as Ti-6Al-4V, which is characterised by higher sensitivity to oxygen and known to be prone to oxygen dissolution, are very strongly impaired when produced by L-PBF if the residual oxygen is not monitored properly [14,15], while other alloys such as $316 \mathrm{~L}$ stainless steel are more robust in this respect $[16,17]$. This underlines the importance of the analysis of the sensitivity of specific alloys to oxygen and nitrogen pick-up and hence powder degradation, and its effect on defect characteristics and the final mechanical properties of as-built material. Thus, it is of interest to evaluate the response of Alloy 718 to different residual oxygen levels and to nitrogen as process atmosphere.

In addition, as for many aerospace applications, AM parts undergo post-AM hot isostatic pressing (HIP) to assure a minimum level of defects [18]. The application of nitrogen as the process gas during L-PBF is of interest, as nitrogen has higher solubility in the matrix than argon and hence can minimize/avoid the risk of porosity re-growth during post-HIP heat treatment and/or application.

In the present work, high-purity argon and nitrogen were used to establish the L-PBF process atmospheres to build Alloy 718 parts, while the residual oxygen level in the process chamber was precisely controlled. The effect of the two gases, argon and nitrogen, and different oxygen levels on the composition, hardness, and microstructure of the Alloy 718 in the as-built state was evaluated.

\section{Materials and Methods}

An EOS M290 (EOS GmbH) L-PBF machine with a build envelope of $250 \times 250 \times$ $325 \mathrm{~mm}^{3}$ was used to produce the material investigated in this study. This system is equipped with a Yb-fiber laser of nominal maximum power of $400 \mathrm{~W}$. Gas atomized Alloy 718 powder provided by Höganäs $A B$ (Sweden), with particle sizes in the range of 15 to $45 \mu \mathrm{m}$ was employed as the feedstock material to build cubes of dimensions $10 \times 10 \times 15 \mathrm{~mm}^{3}$ with the standard parameters developed by the machine manufacturer with a $40 \mu \mathrm{m}$ layer thickness (under the license IN718_PerformanceM291 2.11). The oxygen and nitrogen contents of the as-received powder are listed in Table 1. 
Table 1. Oxygen and nitrogen contents in the cubes built using argon and nitrogen atmospheres at different residual oxygen contents and the virgin Alloy 718 powder. The hardness (HV1) measured on the as-built cubes is also displayed.

\begin{tabular}{ccccc}
\hline Gas & $\mathbf{O}_{\mathbf{2}}$ level & $\mathbf{O}(\mathbf{p p m})$ & $\mathbf{N}(\mathbf{p p m})$ & HV1 \\
\hline Argon & $500 \mathrm{ppm} \mathrm{O}_{2}$ & $316 \pm 38$ & $1091 \pm 43$ & $333 \pm 8$ \\
Argon & $50 \mathrm{ppm} \mathrm{O}_{2}$ & $303 \pm 30$ & $1099 \pm 39$ & $332 \pm 4$ \\
Nitrogen & $500 \mathrm{ppm} \mathrm{O}_{2}$ & $329 \pm 39$ & $1142 \pm 30$ & $334 \pm 3$ \\
Nitrogen & $50 \mathrm{ppm} \mathrm{O}_{2}$ & $293 \pm 24$ & $1148 \pm 32$ & $331 \pm 8$ \\
Virgin powder & N.A. & $472 \pm 13$ & $1495 \pm 4$ & N.A. \\
\hline
\end{tabular}

High-purity technical Argon 5.0 and Nitrogen 5.0, with less than 10 ppm impurities, were used to establish the process conditions. The residual oxygen in the process atmospheres in the process chamber of EOS M290 was controlled by an external oxygen monitoring system, the $A D D$ vanceO2®precision (Linde $\mathrm{GmbH}$ ), details concerning the operating principle of which can be found elsewhere [16,19]. This device samples gas from the vicinity of the baseplate and uses the signal from an electrochemical sensor, which does not exhibit cross-sensitivity to hydrogen and its species, to adjust the incoming flow of fresh gas. The system also features a lambda probe to monitor rapid oxygen variations. In the

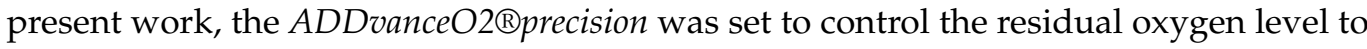
$50 \mathrm{ppm} \mathrm{O}_{2}$ and $500 \mathrm{ppm} \mathrm{O}_{2}$ in both argon and nitrogen atmospheres.

For each atmosphere and oxygen level, three cubes were built. These were removed from the baseplate and mounted in resin to observe their cross-section along the building direction. Then, the samples were ground and polished until a final step with silica suspension to achieve mirror finish. The relative porosity was measured using a light optical microscope (LOM) ZEISS Axioscope 7 on the polished cross-sections of studied cubes, and the software ImageJ was used to obtain the area fraction of pores [20]. The Vickers hardness HV1 (1 kgf) was measured with a DuraScan system (Struers), and the reported values correspond to the average from at least five indentations evenly distributed on the cross-sections. The microstructures were revealed after electro-chemical etching in a $10 \%$ oxalic acid solution using a platinum counter cathode with a potential of $6 \mathrm{~V}$ and studied using a field-emission gun scanning electron microscope (Leo Gemini 1550 SEM), equipped with an energy-dispersive X-ray spectrometer (EDS) INCA X-sight. The contents of oxygen and nitrogen in the bulk of the cubes were measured by combustion analysis with a LECO ON836 (LECO) instrument.

X-ray diffraction (XRD) was conducted on the cubes using a PANalytical X'Pert PRO (Malvern Panalytical) diffractometer with $\mathrm{Cu} \mathrm{K} \alpha$ radiation operated at $45 \mathrm{kV}$ and $40 \mathrm{~mA}$. The diffraction angle was varied from $30^{\circ}$ to $100^{\circ}$. The $\mathrm{XRD}$ results were evaluated using the DIFFRAC.EVA (Bruker) software and the PDF-4+ 2020 database.

The software Thermo-Calc 2021a (Thermo-Calc Software AB) and the TCNI10 (NiAlloys v10.0) database were used to calculate the phase diagram for Alloy 718 and nitrogen. The precipitation module Prisma was also employed using the TCNI10 and MOBNI5 (Ni-Alloys Mobility v5.1) databases to calculate nitride precipitation in Alloy 718.

\section{Results}

\subsection{Chemistry and Hardness}

Table 1 lists the oxygen and nitrogen contents of the virgin Alloy 718 powder and as-built samples produced in argon and nitrogen atmospheres, and their corresponding Vickers hardness. First of all, regardless of the process gas, significant oxygen and nitrogen losses, of about $150 \mathrm{ppm} \mathrm{O}_{2}$, meaning almost $\approx 30 \%$, and $400 \mathrm{ppm} \mathrm{N}_{2}(\approx 25 \%)$, were detected from the virgin feedstock powder to the as-built material. Oxygen loss from the powder to the component has already been reported for other materials such as $316 \mathrm{~L}$ stainless steel in several studies $[16,17]$, and it was attributed to the elimination of oxygen bound to the surface of the powder particles and to an important transfer of oxygen to condensates and spatters. Our earlier work also showed that reduced sample thickness for 316L stainless 
steel can lead to reduced oxygen loss, which is associated to heat accumulation [17]. However, for 316L stainless steel, the nitrogen is typically mostly transferred from the powder to the bulk of the material [16], and it can even be 50 to 100 ppm higher in the bulk (close to $10 \%$ increase). This highlights interesting differences between these two materials when exposed to the L-PBF conditions, which is assumed to be connected to the lower solubility of nitrogen in the austenitic $\gamma$ matrix in case of Alloy 718 compared to iron matrix in case of 316L stainless steel [21,22].

From Table 1, it can be seen that the oxygen loss was slightly enhanced when decreasing the residual oxygen in the process chamber. In addition, the nitrogen concentration is higher-about $50 \mathrm{ppm}$ or $5 \%$ more-for the samples produced under nitrogen compared to the argon samples. This suggests that the higher nitrogen partial pressure limited the nitrogen loss. Despite the reported difference in nitrogen content, the hardness does not vary significantly between the samples. As reported by Cockcroft et al. [23] and A. Mitchell [24], the solubility of nitrogen in wrought Alloy 718 is low and can be calculated to be about $38 \mathrm{ppm}$ at $1700 \mathrm{~K}$ and increases up to $620 \mathrm{ppm}$ at $2000 \mathrm{~K}$, suggesting that nitrogen is mostly present as nitrides or supersaturating the matrix in the studied samples.

\subsection{Microstructure}

The analysis of the polished cross-sections highlighted that both gases allow achieving high density $(>99.9 \%)$, and no defects such as porosity or cracks were detected. Upon etching, the typical microstructure obtained for Alloy 718 produced by L-PBF in the as-built state was revealed; see Figure 1a. The solidification of the $\gamma$ matrix is associated with the segregation to the liquid of elements with low solubility in the matrix such as $\mathrm{Nb}, \mathrm{Mo}$, and Ti. As a result, upon further cooling, Laves and carbides are generally formed in the interdendritic regions, and they can be distinguished by their brighter contrast in Figure 1a. Higher magnification micrographs $(\times 10 \mathrm{k})$ were used to measure the primary dendrite arm spacing (PDAS) of the obtained microstructure. The PDAS varied in a range from 500 to $700 \mathrm{~nm}$, regardless of the process atmosphere, suggesting that the processing gas did not have a significant influence on the solidification conditions for Alloy 718.

Figure 1 also displays examples of the precipitates, which were found sporadically in the $\gamma$ matrix on the cross-section of the as-built cubes. Figure 1a shows Ti-rich nitrides with sharp edges analyzed by EDS mapping, which were typically observed with size in the order of tens of microns. These nitrides are sometimes seen accompanied by spherical Alrich oxides. Some independent spherical $\mathrm{Al}$-rich oxides of a few micrometres in diameter were also identified by point EDS; see Figure 1b. Finally, larger clusters of these nitrides have been observed; see Figure 1c. Such inclusions exhibiting hexagonal faceting have already been reported by Cockcroft et al. [23] for wrought Alloy 718, who mentioned that the seen Al-rich oxides might also contain $\mathrm{Mg}$ and that the titanium nitrides further act as nucleants for carbides [23,25]. Finer Ti-/N-rich precipitates have also been identified, with sizes up to hundreds of nanometres, which are located preferably at the interdendritic regions; see Figure 2. These tend to have more irregular shapes than the faceted micronsized nitrides. 


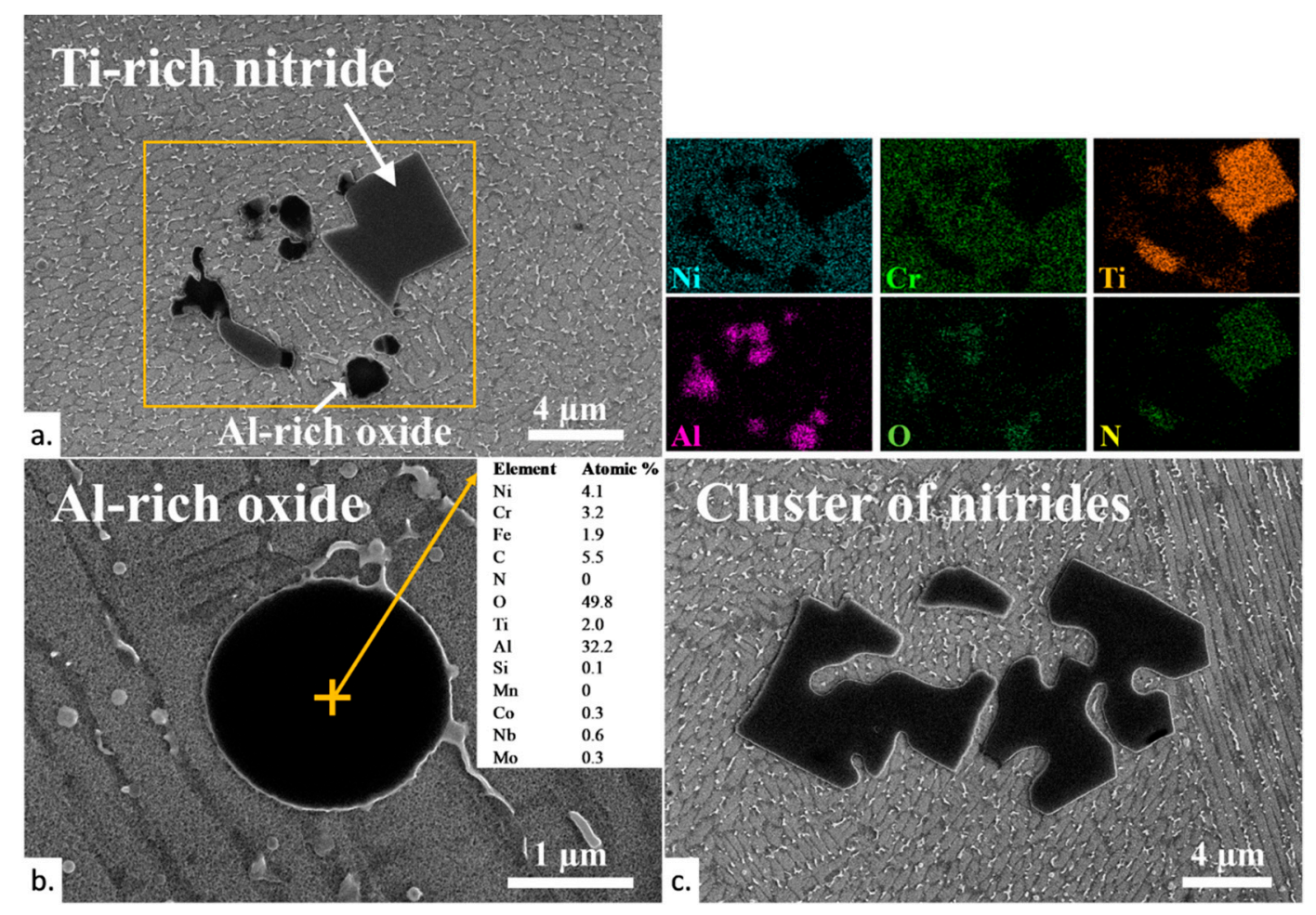

Figure 1. Typically observed inclusions observed on the etched cross-sections of the as-built Alloy 718, regardless of the atmosphere type and purity. (a) Titanium nitride and Al-rich oxides observed on the cross-section of a cube built under argon with 50 ppm residual oxygen. (b) A spherical Al-rich oxide observed on a cube built under nitrogen with 500 ppm residual oxygen. (c) Cluster of nitrides observed on the same cube.
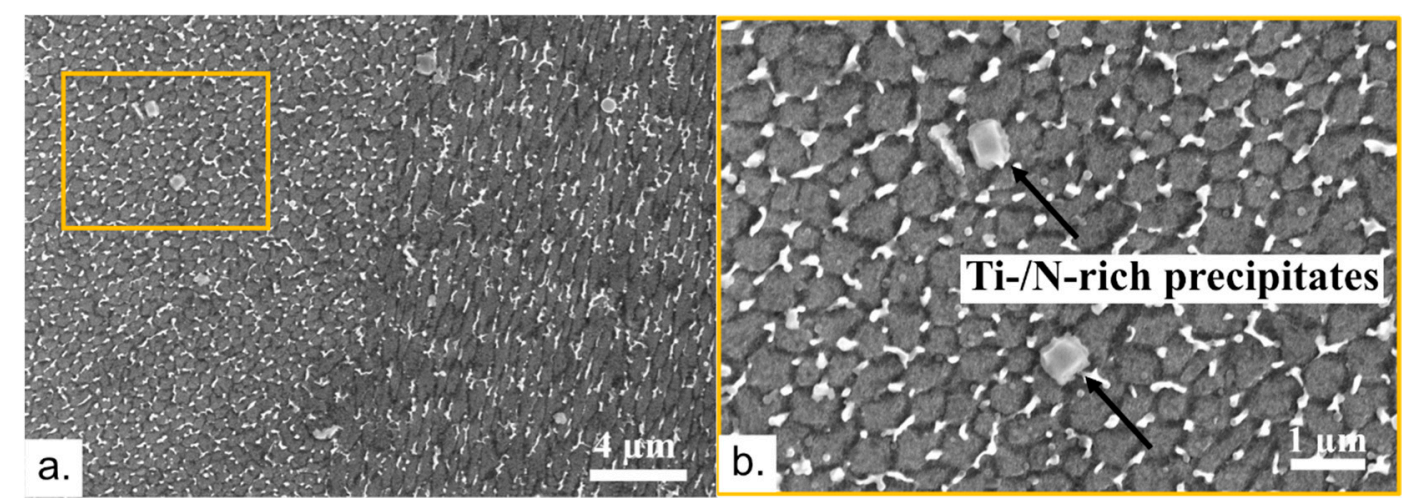

Figure 2. (a) Fine Ti- and N-rich precipitates of more irregular shape randomly distributed within the matrix. (b) These have been identified using EDS and are pointed out by black arrows in the close-up image.

Due to the large size of the observed faceted nitrides, it is assumed that they are inherited from the powder feedstock. Since their melting point is estimated to be above $2900{ }^{\circ} \mathrm{C}$ [26], they are likely unaffected during L-PBF processing. Furthermore, the crosssection of the feedstock metal particles allowed to highlight the presence of bulky nitrides as well as finer ones distinguishable on the polished matrix with their darker contrast; see Figure 3. 

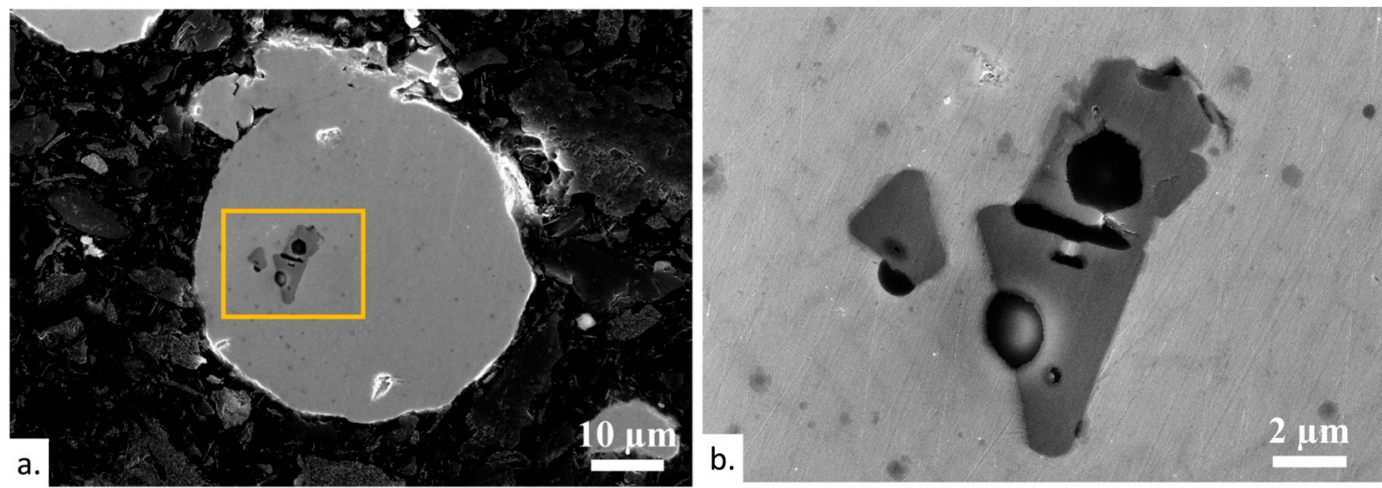

Figure 3. (a) SEM micrograph of the polished cross-section of the gas atomized Alloy 718 powder used as feedstock to produce the samples of this study. (b) Close-up on titanium nitrides and Al-rich oxides characterized by darker contrast.

\subsection{X-ray Diffraction}

Figure 4 shows the XRD patterns of the cubes produced under argon. The main peaks of the $\gamma$ matrix have a high intensity. The close-up on the pattern at low angles suggests that the peak position, intensity, and width of the matrix and secondary phases are similar among the samples produced with different residual oxygen levels under argon. Similar conclusions were derived from the patterns of the cubes produced under nitrogen. Finally, the patterns of the samples produced under argon and nitrogen are very comparable considering the diffraction peaks of the matrix and secondary phases; see Figures 4 and 5 .
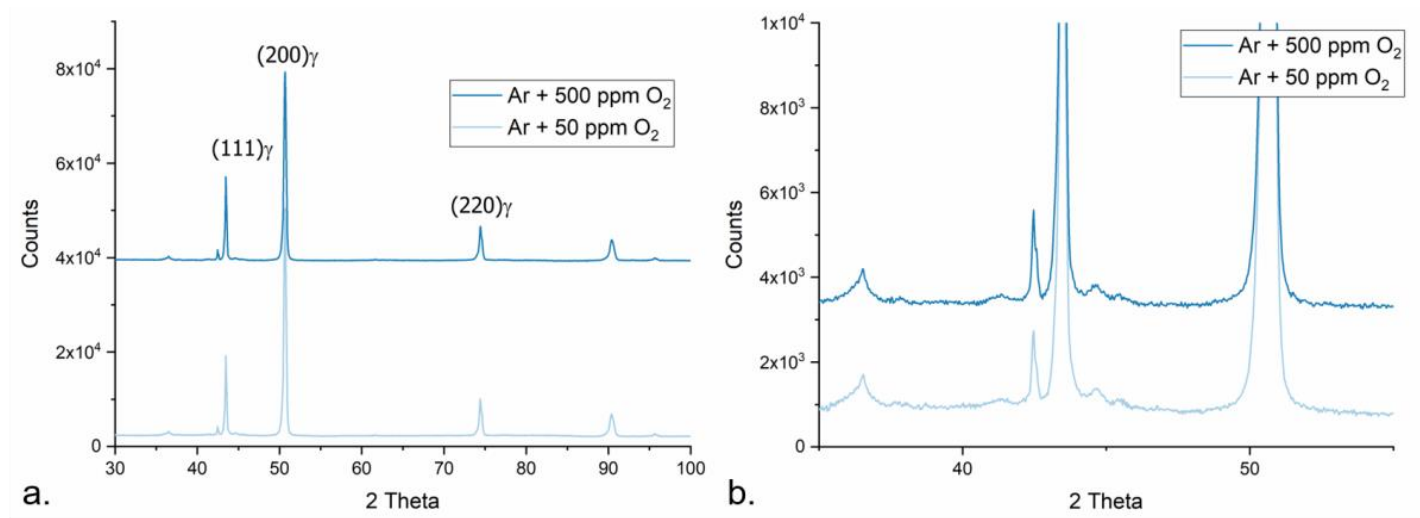

Figure 4. (a) XRD pattern of the as-built cubes produced with argon for different residual oxygen level. (b) Close-up on the patterns in the $35^{\circ}$ to $55^{\circ}$ range.
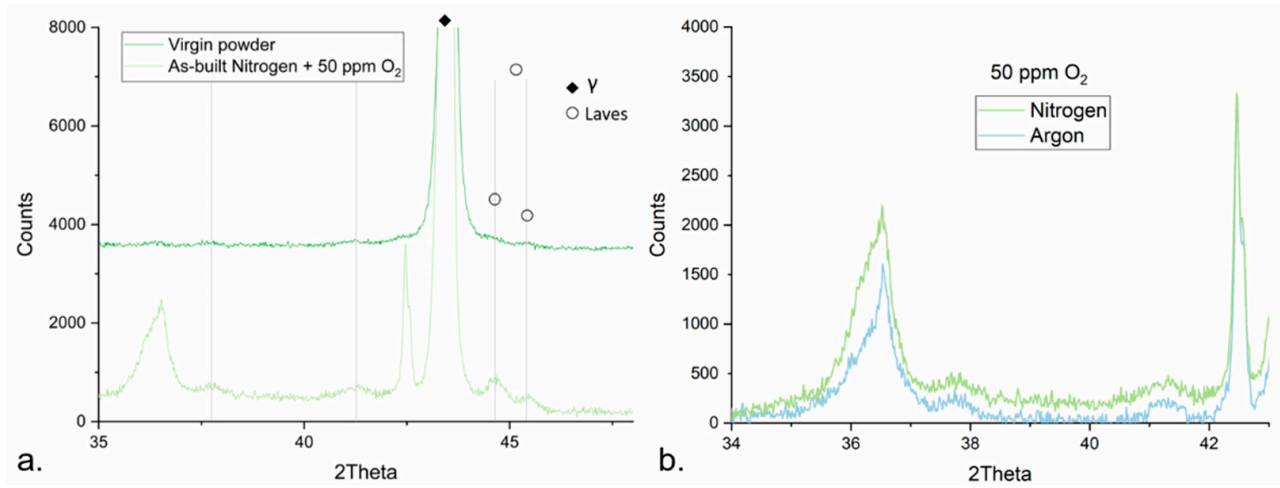

Figure 5. (a) XRD pattern at low angles with indexed peaks of the virgin feedstock Alloy 718 powder used to build the studied samples, together with the XRD pattern of a cube built using nitrogen with 50 ppm residual oxygen. (b) Close-up on the XRD pattern at low diffraction angles of the Alloy 718 cubes built under argon and nitrogen with 50 ppm residual oxygen. 
Figure 5a displays the XRD pattern of the feedstock virgin Alloy 718 powder and the cube produced under nitrogen with $50 \mathrm{ppm} \mathrm{O}_{2}$. Peaks at about $37.8^{\circ}$ and $41.3^{\circ}$ are noted for both, suggesting a transfer of the corresponding phase(s). Reviewing the PDF database allows pointing out candidates for these peaks; however, it should be stressed that correct identification would require additional matching peaks and confirmation using complementary techniques, e.g., transmission electron microscopy (TEM). The pattern of $\mathrm{Ti}_{2} \mathrm{~N}$ with PDF $01-080-3438$ features peaks at approximately $36.8^{\circ}, 37.5^{\circ}$, and $41^{\circ}$. Other candidates with close peaks are nitrides rich in $\mathrm{Cr}$ and $\mathrm{Nb}$ such as $\mathrm{CrNbN}$ and $\mathrm{MoNbN}$. Carbides such as $\mathrm{TiC}$ also have a peak close to $41.7^{\circ}$. Therefore, it appears difficult to distinguish possible nitrides from for example mixed MC carbides. Indeed, MC carbides were shown to be very fine and present in the interdendritic regions in as-built Alloy 718 by Gallmeyer et al. [27] using STEM with EDS.

The produced samples feature additional peaks: a broad peak over the range between $35^{\circ}$ and $37^{\circ}$ and a narrower peak at about $42.5^{\circ}$. The absence of these peaks in the powder suggests that it is either new or transformed product(s) from L-PBF processing. As mentioned above, $\mathrm{Ti}_{2} \mathrm{~N}$ has a peak at $36.8^{\circ}$. Other candidates such as TiN (PDF 00-0381420) and $\mathrm{TiN}_{0.9}$ (PDF 00-031-1403) exhibit peaks at about $36.7^{\circ}$ and $42.6^{\circ}$. It appears that $\mathrm{C}_{0.4} \mathrm{~N}_{0.7} \mathrm{Ti}$ (PDF 00-042-1488) also has peaks at $36.5^{\circ}$ and $42.3^{\circ}$. The lower angle diffraction peak appears rather broad and asymmetric, suggesting the possible overlap of different phases. From the database, an enrichment in carbon of the nitrides is again suspected, when for instance considering $\mathrm{C}_{0.7} \mathrm{~N}_{0.3} \mathrm{Ti}$ (PDF 00-042-1489) with a peak at $36.2^{\circ}$ and $\mathrm{TiC}$ (PDF 00-031-1400) with a peak at $35.9^{\circ}$. Hence, it can be concluded that the low-intensity peaks observed between $35^{\circ}$ and $42.5^{\circ}$ suggest the potential presence of mixed MC carbides and/or carbonitrides, the proper identification of which requires detailed study using e.g., TEM or atom probe tomography (APT) and was outside the scope of this work.

\section{Discussion}

Nitride and oxide inclusions of similar morphologies were identified in the produced material and the feedstock powder and support their transfer during L-PBF. Slight differences between the XRD patterns of the as-built material and of the powder suggest that possibly nitrides undergo some limited compositional or structural changes during L-PBF processing. From Figure 1c, it can be assumed that coarse nitrides possibly agglomerate under the melt pool convection. Overall, their distribution appeared homogeneous in the built volume, regardless of the process atmosphere or its purity.

The observation of the cross-section of the uppermost region of the cubes highlights an accumulation of inclusions at the top of the last deposited layer; see Figure 6a. The direct examination of the top surface reveals the important presence of oxides at the peripheries of the melt tracks; see Figure 6b. Line scan EDS on the top surface further confirms the presence of Al-rich oxides and Ti-rich nitrides in these regions; see Figure 7a. The EDS mapping over a nitride precipitate uncovers the additional presence of oxide patches enriched in $\mathrm{Ni}$ and $\mathrm{Cr}$, possibly of spinel type; see Figure $7 \mathrm{~b}$. These oxide features were also observed on the top surface of the cubes.

Such accumulation of inclusions has already been reported for Alloy 718 produced by other AM processes. Gruber et al. [28] revealed the transport and accumulation of oxide and nitride inclusions, which cluster in the liquid metal, at the top and side surfaces of components built by EBM. As a result, a refining effect was proposed explaining almost a $50 \%$ reduction in oxygen content in the EBM-produced compact compared to the feedstock powder, which is valid even in case of powder re-use after 30 cycles [28]. It should be emphasized that TiN and $\mathrm{Al}_{2} \mathrm{O}_{3}$ are expected to float in the liquid metal because of their low densities in comparison to the metal matrix (i.e., TiN: $5.4 \mathrm{~g} / \mathrm{cm}^{3}, \mathrm{Al}_{2} \mathrm{O}_{3}: 4.0 \mathrm{~g} / \mathrm{cm}^{3}$, Alloy 718: $8.2 \mathrm{~g} / \mathrm{cm}^{3}$ ) [26]. However, as suggested by Polonsky et al. [29], the rapid cooling and solidification rates during AM processing will tend to limit the effect of buoyancy, and instead, the Marangoni flow is more likely to be responsible for the displacement and clustering of the inclusions. As shown by Gruber et al. [28], strong oxide accumulation 
on the top of the specimen and specimen contour regions makes chemical analysis of the EBM-fabricated compacts very sensitive to the sampling of the specimens for chemical analysis. Since the chemistry reported in Table 1 was measured in samples extracted from the bulk without surfaces, additional analyses were conducted to measure the oxygen content close to the surfaces, by cutting and analyzing separately the side and top surfaces of the Argon $500 \mathrm{ppm} \mathrm{O}_{2}$ cube. The results highlight an oxygen level for the top and side surfaces of $20 \mathrm{ppm}$ more compared to the bulk measurements reported in Table 1 (only $6 \%$ increase). Therefore, the accumulation of inclusions is only slightly contributing to the oxygen loss from powder to the component. Nitrogen was analyzed in a similar manner for the surfaces and appeared comparable to the bulk measurements.

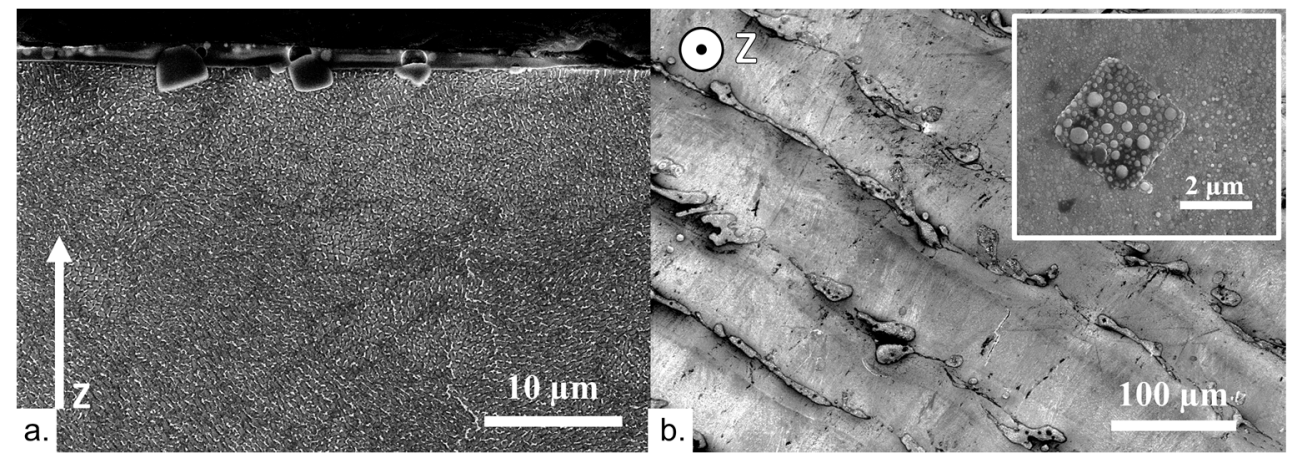

Figure 6. (a) Micrograph of the cross-section at the top of the uppermost last deposited layer, and (b) top view of a cube produced under argon and $50 \mathrm{ppm}$ residual $\mathrm{O}_{2}$. The insert depicts the presence of titanium-rich nitrides on the top surface.

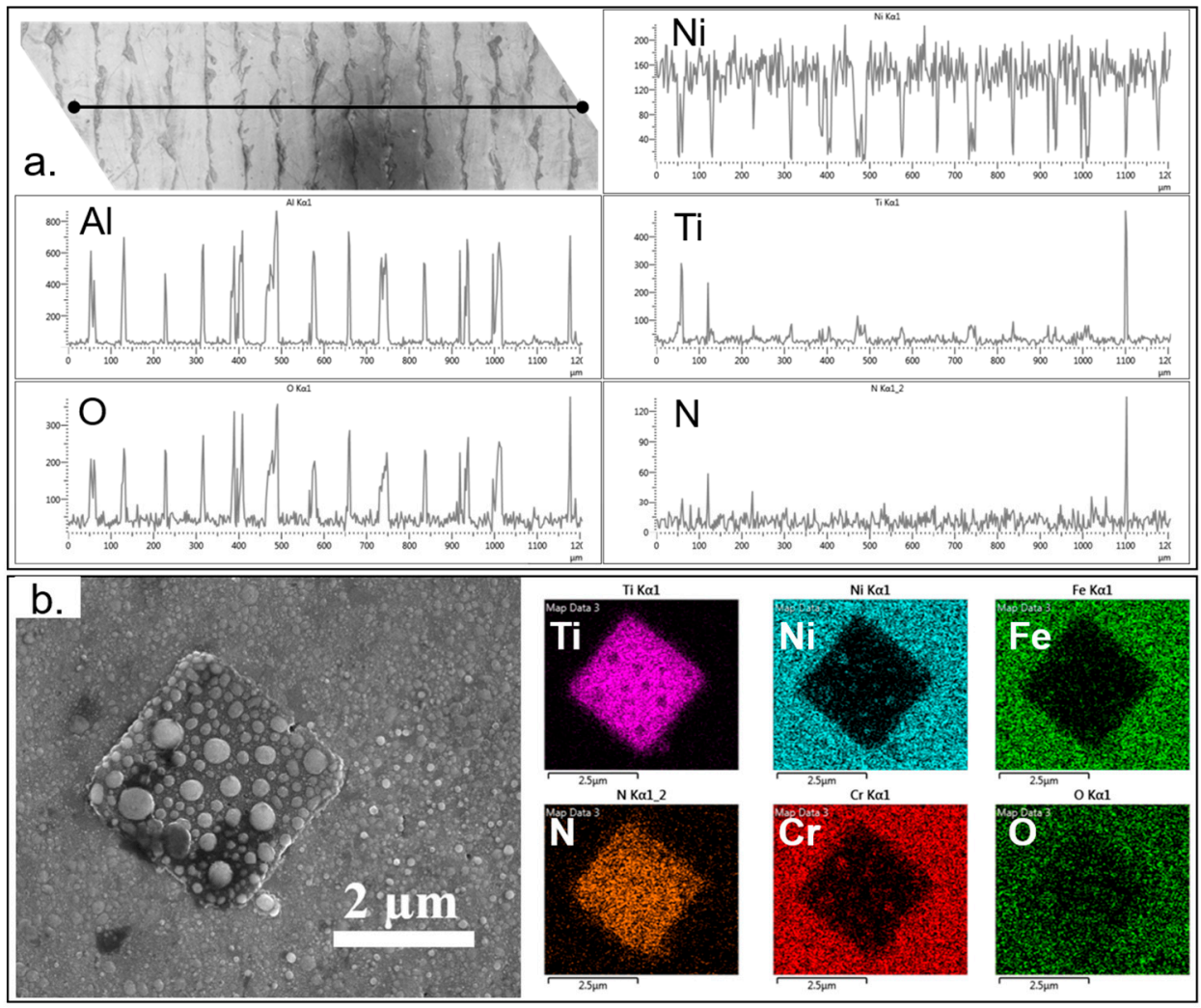

Figure 7. (a) EDS line scan over the top surface of a cube produced under argon and $50 \mathrm{ppm}$ residual $\mathrm{O}_{2}$. (b) EDS map over a titanium nitride observed on the top surface. 
All the Alloy 718 samples produced by L-PBF have a nitrogen content reduced by approximately $25 \%$ in comparison to the feedstock powder (e.g., from $1495 \mathrm{ppm} \mathrm{N} \mathrm{N}_{2}$ in the powder to $1142 \mathrm{ppm} \mathrm{N}_{2}$ in the cube produced under nitrogen and $500 \mathrm{ppm}_{2}$ ). Since the nitrogen content appeared unchanged between the bulk and the surfaces, it is proposed that nitrogen could be lost during melting while L-PBF processing. It should be underlined again that nitrogen solubility in Alloy 718 is low. Figure 8 displays the phase diagram of Alloy 718 in dependance on nitrogen content calculated with Thermo-Calc 2021a software and the TCNI10 database. The phase diagram confirms that the solubility of nitrogen in solid Alloy 718 is very low (approximately $0.0005 \mathrm{wt} \%$ at $1000{ }^{\circ} \mathrm{C}$ ), and it is the highest in the liquid phase. Overlaid are four isobars showing the equilibrium nitrogen concentration and phase(s) at a given temperature. The highest nitrogen pressure of 1 bar corresponds to a nitrogen-rich L-PBF environment (e.g., $100 \% \mathrm{~N}_{2}$ ). A pressure of 0.78 bar corresponds to the nitrogen partial pressure of air. Finally, 0.002 bar correspond to the nitrogen partial pressure of an L-PBF environment established by purging the initial air with argon, until achieving $500 \mathrm{ppm} \mathrm{O}_{2}$, and also resulting in the dilution of other impurities including nitrogen (keeping its initial ratio with oxygen of about 4). At high temperatures, about $2000{ }^{\circ} \mathrm{C}$, and under thermodynamic equilibrium, the melt contains $0.1 \mathrm{wt} \%(1000 \mathrm{ppm})$ nitrogen under 1 bar of $\mathrm{N}_{2}$ compared to only $0.003 \mathrm{wt} \%$ (30 ppm) under 0.002 bar of $\mathrm{N}_{2}$ when using $\mathrm{Ar}$ as the main process gas. However, because of the rapid cooling conditions during L-PBF (approximately $10^{7} \mathrm{~K} / \mathrm{s}$ [13]), the melt pool lifetime is very limited. Still, the calculated phase diagram allows pointing out that the nitrogen equilibrium concentration is higher for high nitrogen pressure (e.g., at $1100{ }^{\circ} \mathrm{C}$, approximately $2.5 \mathrm{wt} \% \mathrm{~N}_{2}$ for 1 bar, and $0.5 \mathrm{wt} \% \mathrm{~N}_{2}$ for $0.002 \mathrm{bar}$ ). This could explain the slightly reduced nitrogen loss in the samples produced under nitrogen gas. The presence of $\mathrm{Nb}$ - and Ti-rich carbonitrides is predicted by the thermodynamic calculation. In general, the lower nitrogen levels obtained in the built cubes compared to those expected from Figure 8 can be explained by the rapid cooling of the deposited material.

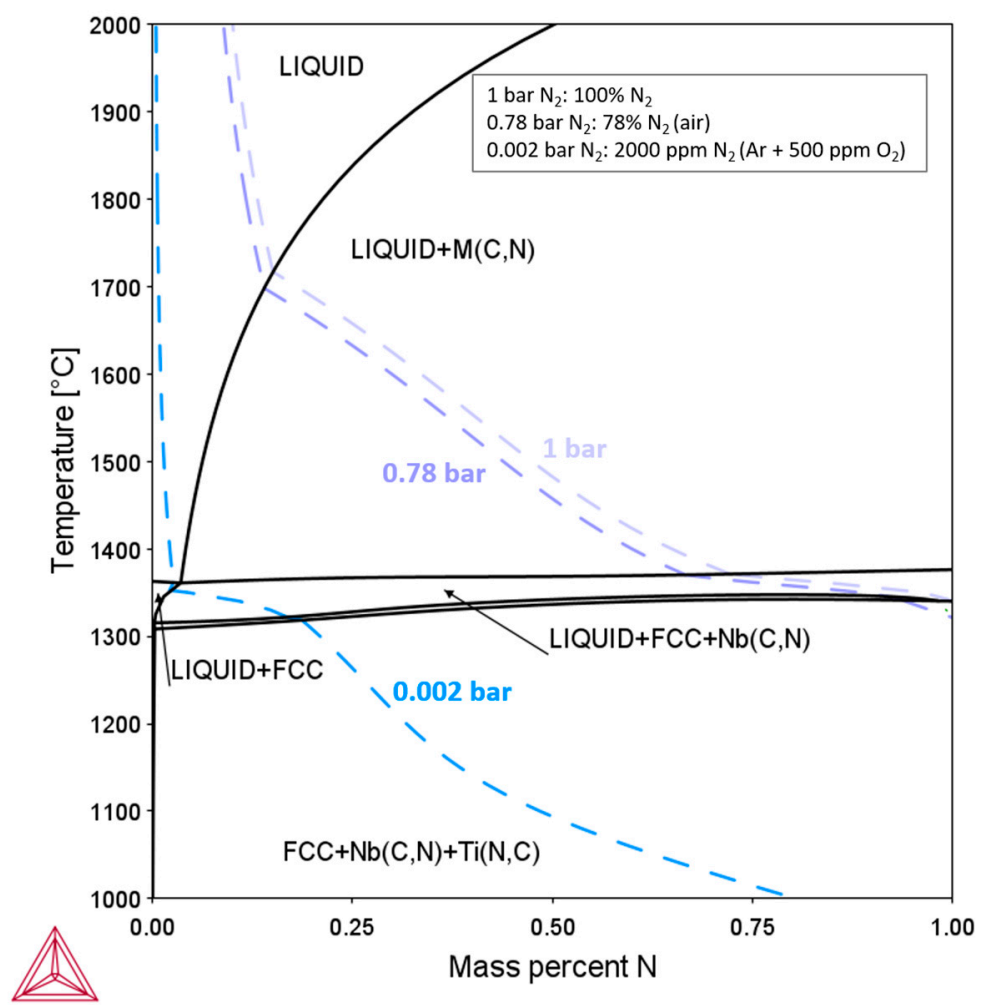

Figure 8. Phase diagram calculated using Thermo-Calc for Alloy 718 and nitrogen along with nitrogen equilibrium isobars. 
In order to explain the origin of the coarse nitride inclusions observed in Figure 1, additional precipitation calculations with Thermo-Calc precipitation module Prisma, using the TCNI10 (Ni-Alloys v10.0) and MOBNI5 (Ni-Alloys Mobility v5.1) databases, were performed and clearly show that nitride precipitation during L-PBF is expected to be very limited and thus not probable. Calculations for the high cooling rates experienced during L$\mathrm{PBF}$ are not yet possible/reliable, and therefore, cooling of the $\gamma$ phase (containing $0.01 \mathrm{wt} . \%$ of N) from 1400 to $900{ }^{\circ} \mathrm{C}$ with a rate of $10^{\circ} \mathrm{C} / \mathrm{s}$ was instead considered. Bulk nucleation of spherical morphology nitrides was selected, and an interfacial energy of $0.4 \mathrm{~J} / \mathrm{m}^{2}$ was defined. The achieved precipitate volume fraction is very low, i.e., approximately 0.005 after $50 \mathrm{~s}$. Figure 9 displays the calculated resulting number density distribution of precipitates (i.e., number of particles per unit volume) as a function of their size. It can be seen that even for this cooling rate, several order of magnitude lower than those experienced during L-PBF, a very small fraction of nitrides may form, of submicron size. It should be underlined that these calculations are very sensitive to the used interfacial energy. Herein, it was taken as the mean interfacial energy derived from the calculated property model considering the matrix and the nitride phases for the considered temperature range.

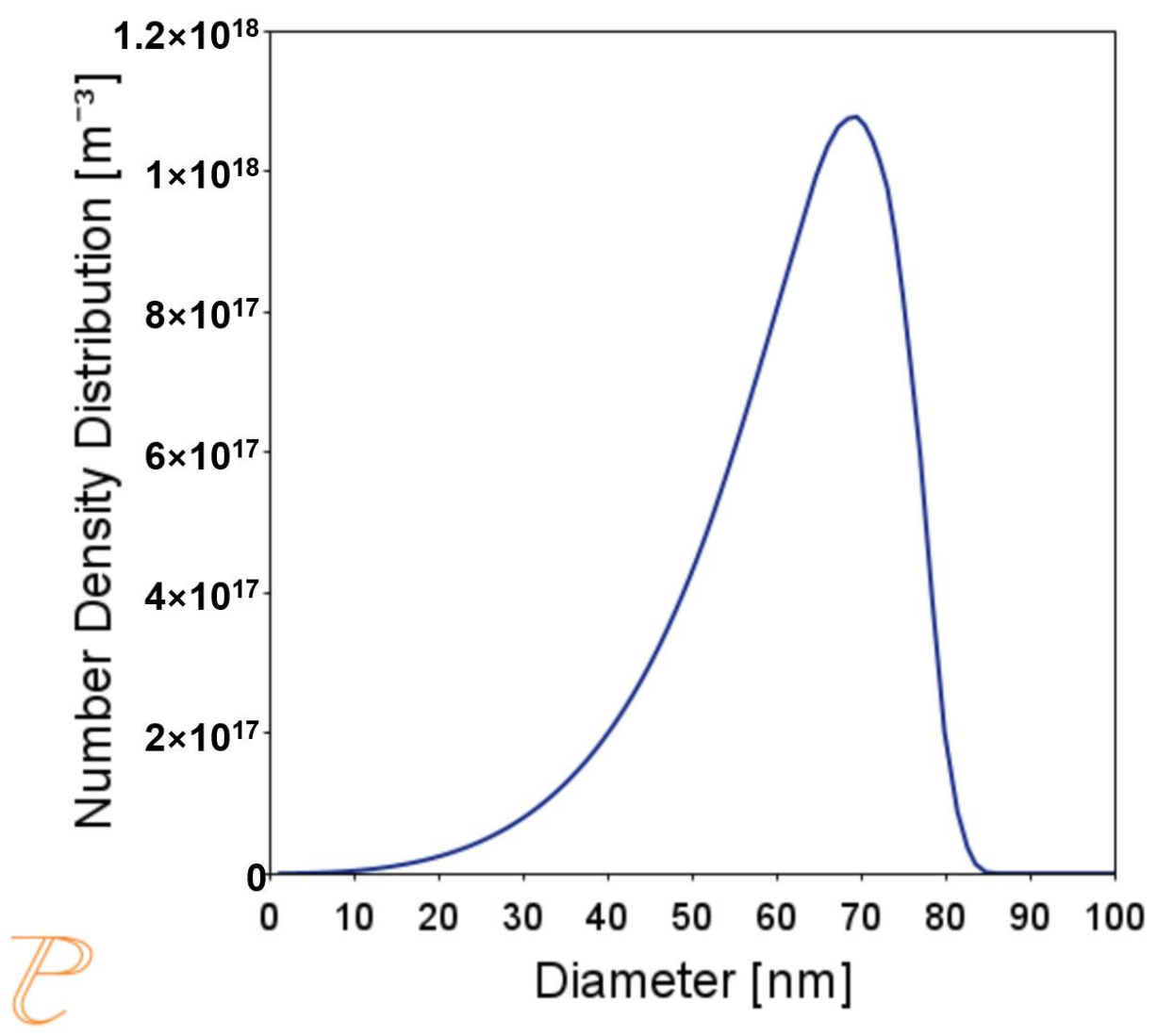

Figure 9. Thermo-Calc calculation using the precipitation module TC-PRISMA of the resulting number density distribution of nitride precipitates in the matrix as a function of their diameter after $50 \mathrm{~s}$.

The presented results are promising, since the microstructure and hardness of the material produced under nitrogen, which is an abundant gas, are similar to those of the material produced with traditional argon. It should be underlined that the use of nitrogen as process gas could be preferred over that of argon, for example, to enhance effective pore closure during HIP, and thus be used in strategies to increase process productivity. Indeed, it has been shown that some materials used at high temperatures can be sensitive to thermally induced porosity (TIP) [30,31], which is the pore regrowth under high internal pressure, when the gases inside the defects have a low solubility in the material (such as argon). Finally, the possible use of nitrogen to control the L-PBF material composition 
should be further investigated and considered as a function of laser parameters, melt pool size, and its lifetime. Conducting a similar work as the presented one, with the virgin feedstock powder of lower oxygen and nitrogen contents, would also complete the current understanding of impurities and inclusions transfer occurring during L-PBF of Alloy 718.

\section{Conclusions}

The present work gives insight into the transfer of impurities and inclusions such as nitrides and oxides from the powder feedstock to the produced components during L-PBF of Alloy 718. In addition, both tested process gases, argon and nitrogen, allowed producing high-density material using the standard laser parameters developed by the machine manufacturer, which is promising for the study, and the development of more complex gas mixtures for L-PBF. The following conclusions from the investigations could be drawn:

- Processing of Alloy 718 powder under both argon and nitrogen resulted in the nitrogen loss of about $25 \%(\approx 400 \mathrm{ppm})$ in comparison to the feedstock powder. High-purity nitrogen led to a slightly reduced nitrogen loss from the powder to the deposited material, with about $50 \mathrm{ppm}(5 \%)$ higher $\mathrm{N}_{2}$ compared to the material produced under argon. This is explained by the increased nitrogen solubility for higher nitrogen partial pressure as calculated with Thermo-Calc.

- Using both high-purity argon and nitrogen led to about 30\% loss in oxygen compared to the powder feedstock. Reducing the residual oxygen in the process atmosphere from 500 to $50 \mathrm{ppm}$ during L-PBF processing resulted only in a slight decrease in the oxygen content in the part in the range of 10 to $30 \mathrm{ppm} \mathrm{O}_{2}$.

- Micron-sized nitrides and Al-rich oxide inclusions and their clusters were observed throughout the samples cross-sections, and their origin was confirmed to be connected to the virgin powder, where similar features were observed as well. The transfer of these inclusions is connected to their high melting temperature and thermodynamic stability, leading to their conservation along the process chain.

- Preferential accumulation of nitrides and oxide inclusions was observed on the top surfaces close to the scan track edges, confirming their re-distribution during L-PBF processing along the specimen height.

- Kinetic calculations confirm limited changes in nitride size observed between the powder and the produced samples, as the precipitation of nitrides was shown to be insignificant for the cooling rate of $10 \mathrm{~K} / \mathrm{s}$, which is several orders of magnitude lower than that typically experienced by the L-PBF deposited material $\left(10^{7} \mathrm{~K} / \mathrm{s}\right)$, and hence, nitride precipitation during L-PBF processing can be neglected.

- The small differences in composition between the samples produced under argon and nitrogen did not impact their Vickers hardness. Further assessment of the mechanical properties of the produced material, at room and elevated temperatures after post heat treatment, is recommended to fully understand the potential effect of the applied processing atmospheres.

Author Contributions: C.P.: conceptualization, methodology, investigation, writing—original draft, project administration; A.M.: methodology, investigation, resources; S.D.-L.G.: methodology, investigation, resources; E.H.: conceptualization, funding acquisition, writing-review and editing, supervision; All authors have read and agreed to the published version of the manuscript.

Funding: The work was performed in the framework of the Centre for Additive Manufacturing-Metal $\left(\mathrm{CAM}^{2}\right)$ hosted by Chalmers University of Technology, supported by VINNOVA (grant number: 2016-05175).

Institutional Review Board Statement: Not applicable.

Informed Consent Statement: Not applicable.

Data Availability Statement: Not applicable. 
Acknowledgments: Special thanks are addressed to Yu Cao and Eric Tam for their support with the interpretation of XRD results. This work was conducted in the framework of the Centre for Additive Manufacturing-Metal $\left(\mathrm{CAM}^{2}\right)$ and Innoglobe supported by the Swedish Governmental Agency of Innovation Systems (VINNOVA).

Conflicts of Interest: The authors declare no conflict of interest.

\section{References}

1. Reed, R.C. The Superalloys: Fundamentals and Applications; Cambridge University Press: Cambridge, UK, 2009; ISBN 978-0-52107011-9.

2. Siddall, R.J. Comparison of the Attributes of VIM + ESR and VIM + VAR Alloy 718. Miner. Met. Mater. Soc. 1991, $29-41$.

3. Cedergren, S.; Nyborg, L.; Sjöberg, G. The effects of grain size and feed rate on notch wear and burr formation in wrought Alloy 718. Int. J. Adv. Manuf. Technol. 2012, 67, 1501-1507. [CrossRef]

4. Watring, D.S.; Benzing, J.T.; Hrabe, N.; Spear, A.D. Effects of laser-energy density and build orientation on the structure - property relationships in as-built Inconel 718 manufactured by laser powder bed fusion. Addit. Manuf. 2020, 36, 101425. [CrossRef]

5. Luo, S.; Huang, W.; Yang, H.; Yang, J.; Wang, Z.; Zeng, X. Microstructural evolution and corrosion behaviors of Inconel 718 alloy produced by selective laser melting following different heat treatments. Addit. Manuf. 2019, 30, 100875. [CrossRef]

6. Deng, D.; Peng, R.L.; Brodin, H.; Moverare, J. Microstructure and mechanical properties of Inconel 718 produced by selective laser melting: Sample orientation dependence and effects of post heat treatments. Mater. Sci. Eng. A 2018, 713, 294-306. [CrossRef]

7. Wang, X.; Chou, K. Effects of thermal cycles on the microstructure evolution of Inconel 718 during selective laser melting process. Addit. Manuf. 2017, 18, 1-14. [CrossRef]

8. Mostafa, A.; Rubio, I.P.; Brailovski, V.; Jahazi, M.; Medraj, M. Structure, texture and phases in 3D printed IN718 alloy subjected to homogenization and HIP treatments. Metals 2017, 7, 196. [CrossRef]

9. Jiang, R.; Mostafaei, A.; Pauza, J.; Kantzos, C.; Rollett, A.D. Varied heat treatments and properties of laser powder bed printed Inconel 718. Mater. Sci. Eng. A 2019, 755, 170-180. [CrossRef]

10. Jiang, R.; Mostafaei, A.; Wu, Z.; Choi, A.; Guan, P.; Chmielus, M.; Rollett, A.D. Effect of heat treatment on microstructural evolution and hardness homogeneity in laser powder bed fusion of alloy 718. Addit. Manuf. 2020, 35, 101282. [CrossRef]

11. Gruber, H.; Henriksson, M.; Hryha, E.; Nyborg, L. Effect of Powder Recycling in Electron Beam Melting on the Surface Chemistry of Alloy 718 Powder. Metall. Mater. Trans. A 2019, 50, 4410-4422. [CrossRef]

12. Hryha, E.; Shvab, R.; Gruber, H.; Leicht, A.; Nyborg, L. Surface Oxide State on Metal Powder and its Changes during Additive Manufacturing: An Overview. La Metall. Ital. 2018, 3, 34-39.

13. Pauzon, C.; Raza, A.; Hryha, E.; Forêt, P. Oxygen balance during laser powder bed fusion of Alloy 718. Mater. Des. 2021, 201, 109511. [CrossRef]

14. Dietrich, K.; Diller, J.; Dubiez-le Goff, S.; Bauer, D.; Forêt, P. The influence of oxygen on the chemical composition and mechanical properties of Ti-6Al-4V during laser powder bed fusion (L-PBF). Addit. Manuf. 2020, 32, 100980. [CrossRef]

15. Pauzon, C.; Dietrich, K.; Forêt, P.; Dubiez-Le Goff, S.; Hryha, E.; Witt, G. Control of residual oxygen of the process atmosphere during laser-powder bed fusion processing of Ti-6Al-4V. Addit. Manuf. 2021, 38, 101765. [CrossRef]

16. Pauzon, C.; Hryha, E.; Forêt, P.; Nyborg, L. Effect of argon and nitrogen atmospheres on the properties of stainless steel 316L parts produced by laser-powder bed fusion. Mater. Des. 2019, 107873. [CrossRef]

17. Pauzon, C.; Leicht, A.; Klement, U.; Forêt, P.; Hryha, E. Effect of the process gas and scan speed on the properties and productivity of thin 316L structures produced by laser-powder bed fusion. Metall. Mater. Trans. A 2020, 51, 5339-5350. [CrossRef]

18. Tillmann, W.; Schaak, C.; Nellesen, J.; Schaper, M.; Aydinöz, M.E.; Hoyer, K.P. Hot isostatic pressing of IN718 components manufactured by selective laser melting. Addit. Manuf. 2017, 13, 93-102. [CrossRef]

19. Forêt, P.; Bauer, D. Effect of Process Gas and Powder on AlSiMg Powder Bed Fusion Processed Parts for the Aerospace Industry. In Proceedings of the European Congress and Exhibition on Powder Metallurgy. European PM Conference Proceedings, Shrewsbury, Hong Kong, 9-13 October 2016; pp. 1-6.

20. ImageJ: Image Processing and Analysis in Java. Available online: https:/ /imagej.nih.gov/ij/index.html (accessed on 2 March 2020).

21. Somers, M.A.J.; Christiansen, T.L.; Winther, G. Expanded austenite; from fundamental understanding to predicting compositionand stress-depth profiles. In Proceedings of the European Conference on Heat Treatment (ECHT 2018), Friedrichshafen, Germany, 12-13 April 2018; pp. 92-101.

22. Rawers, J.C.; Frisk, K.; Govier, D. Nitrogen in pressure-diffused powder iron alloys. Mater. Sci. Eng. A 1994, 177, $243-251$. [CrossRef]

23. Cockcroft, S.L.; Degawa, T.; Mitchell, A.; Tripp, D.W.; Schmalz, A. Inclusion Precipitation in Superalloys. Superalloys 2012, 1992, 577-586. [CrossRef]

24. Mitchell, A. Nitrogen in Superalloys. Adv. Mater. Process Eng. Lab. 2004, 24, 101-110. [CrossRef]

25. Mitchell, A.; Schmalz, A.J.; Schvezov, C.; Cockroft, S.L. The Precipitation of Primary Carbides in Alloy 718. Superalloys 1994, 718, 65-78.

26. Haynes, W.M.; Lide, D.R.; Bruno, T.J. CRC Handbook of Chemistry and Physics; CRC Press: Boca Raton, FL, USA, 2004; ISBN-10 1498754287, ISBN-13 9781498754286. 
27. Gallmeyer, T.G.; Moorthy, S.; Kappes, B.B.; Mills, M.J.; Amin-Ahmadi, B.; Stebner, A.P. Knowledge of process-structure-property relationships to engineer better heat treatments for laser powder bed fusion additive manufactured Inconel 718. Addit. Manuf. 2020, 31, 100977. [CrossRef]

28. Gruber, H.; Luchian, C.; Hryha, E.; Nyborg, L. Effect of Powder Recycling on Defect Formation in Electron Beam Melted Alloy 718. Metall. Mater. Trans. A Phys. Metall. Mater. Sci. 2020, 51, 2430-2443. [CrossRef]

29. Polonsky, A.T.; Echlin, M.P.; Lenthe, W.C.; Dehoff, R.R.; Kirka, M.M.; Pollock, T.M. Defects and 3D structural inhomogeneity in electron beam additively manufactured Inconel 718. Mater. Charact. 2018, 143, 171-181. [CrossRef]

30. Rashidi, M.; Liljestrand, F.; Nyborg, L.; Hryha, E. Porosity closure using hot isostatic pressing and re-opening of porosity during subsequent heat treatment of additively manufactured IN718. In Proceedings of the Euromat, Stockholm, Sweden, 1-5 September 2019.

31. Tammas-Williams, S.; Zhao, H.; Léonard, F.; Derguti, F.; Todd, I.; Prangnell, P.B. XCT analysis of the influence of melt strategies on defect population in Ti-6Al-4V components manufactured by Selective Electron Beam Melting. Mater. Charact. 2015, 102, 47-61. [CrossRef] 